\title{
Assessing surface water flood risk and management strategies under future climate change: insights from an Agent-Based Model
}

\author{
K. Jenkins ${ }^{\text {a }}$, S. Surminski ${ }^{\text {b }}$ J. Hall ${ }^{\mathrm{a}}$, and F. Crick ${ }^{\mathrm{b}}$ \\ ${ }^{a}$ Environmental Change Institute (ECI), University of Oxford, Oxford University Centre for the \\ Environment, South Parks Road, Oxford, OX1 3QY, UK. katie.jenkins@ eci.ox.ac.uk; \\ jim.hall@eci.ox.ac.uk \\ ${ }^{\mathrm{b}}$ Grantham Research Institute on Climate Change and the Environment, The London School of \\ Economics and Political Science, Floor 11, Tower 3, Clement's Inn, London, WC2A 2AZ, UK. \\ s.surminski@1se.ac.uk; f.d.Crick@1se.ac.uk
}

Corresponding author: Katie Jenkins (katie.jenkins@eci.ox.ac.uk)

Final version accepted for publication 26 March 2017.

Science of The Total Environment. 595, 159-168pp.

http://dx.doi.org/10.1016/j.scitotenv.2017.03.242

\begin{abstract}
Climate change and increasing urbanization are projected to result in an increase in surface water flooding and consequential damages in the future. In this paper, we present insights from a novel Agent Based Model (ABM), applied to a London case study of surface water flood risk, designed to assess the interplay between different adaptation options; how risk reduction could be achieved by homeowners and government; and the role of flood insurance and the new flood insurance pool, Flood Re, in the context of climate change. The analysis highlights that while combined investment in property-level flood protection and sustainable urban drainage systems reduce surface water flood risk, the benefits can be outweighed by continued development in high risk areas and the effects of climate change. In our simulations, Flood Re is beneficial in its function to provide affordable insurance, even under climate change. However, the scheme does face increasing financial pressure due to rising surface water damages. If the intended transition to risk-based pricing is to take place then a determined and coordinated strategy will be needed to manage flood risk, which utilises insurance incentives, limits new development, and supports resilience measures. Our modelling approach and findings are highly relevant for the ongoing regulatory and political approval process for Flood Re as well as for wider discussions on the potential of insurance schemes to incentivise flood risk management and climate adaptation in the UK and internationally.
\end{abstract}

Keywords: Surface water flooding; risk; insurance; climate change; adaptation 


\section{Introduction}

\subsection{Surface water flood risk}

Surface water flood risk (sometimes known as 'urban' or 'storm water' flooding) emerges from the interplay between biophysical and human factors (Hall et al., 2003). Biophysical factors determine the frequency, duration and intensity of rainfall, and the runoff that occurs when rain hits the ground. Rainfall may be infiltrated into the ground, but in urban areas with impermeable surfaces rain water will flow on the surface in directions modified by the form of buildings and streets and will accumulate at locations with low topographical elevation. These processes are modified by drains that are designed to convey water away from urban areas on the surface or in pipes (Blanc et al., 2012). Risk will also be dependent on the vulnerability of the area and population exposed to the event (Hall et al., 2005) and, where in place, the effectiveness of surface water management interventions.

Worldwide urban areas are becoming increasingly vulnerable to surface water flooding due to rapid urbanisation, installation of complex infrastructure, and changes in the precipitation patterns caused by anthropogenic climate change (Willems et al., 2012). For example, Hammond et al., (2015) highlight recent surface water flood events in Brisbane in January 2011, in Bangkok during the 2011 monsoon season, and in Beijing in July 2012. Impacts can be significant, with disruption of services, damage to critical infrastructure and property, as well as wider societal impacts. Given future projections in population, urbanisation, and anthropogenic climate change such events and their impacts are likely to be exasperated in the future. The Intergovernmental Panel on Climate Change (IPCC, 2014) ascertain with a very high level of confidence that in urban areas climate change is projected to increase risks for people, assets, economies and ecosystems, including risks from extreme precipitation.

In the UK context this is significant as flooding is already recognized as one of the most common and costliest natural disasters and is listed as a major risk on England's National Risk Register (Cabinet Office, 2015). The UK Climate Change Risk Assessment (CCRA) has identified flood risk management as one of the priority areas for action over the next five years, as flood risks are projected to increase significantly across the UK throughout this century (Defra, 2012). Surface water flooding is already listed as the most likely cause of damage to properties in the UK National Risk Register, with estimated annual costs of $£ 1.3-£ 2.2$ billion (Defra, 2011).

The consequences of surface water flooding were demonstrated by the summer floods of 2007, which affected England and caused the country's largest peacetime emergency since World War II. The total economic cost of the floods was estimated to be $£ 3.2$ billion (2007 prices), with $£ 2.5$ billion borne by households at a cost of $£ 1.8$ billion to insurers (Environment Agency, 2010). These floods differed in scale and type from recent floods in that a much higher proportion of flooding than normal came from surface water flooding rather than rivers. The Pitt Review (Pitt, 2008), conducted to provide lessons and recommendations in the aftermath of the 2007 summer floods, highlighted major gaps in the understanding and management of risks from surface water flooding. Similar concerns have also been raised across Europe, recognizing that some member states have in the past given much lower priority to this type of flood risk, meaning that vulnerability has crept upwards (European Water Association, 2009). 
The Pitt Review emphasized the need for urgent and fundamental changes in the way the UK is adapting to the likelihood of more frequent and intense periods of heavy rainfall. Findings presented in the UK Climate Projections (UKCP09) show that as a result of climate change the UK weather in the upcoming century will be characterized by more days of extreme precipitation (IPCC, 2013). These changing precipitation patterns are expected to result in an increase in surface water flood events in the UK (Ramsbottom et al., 2012). Combined with an increasing pattern of urbanization Defra estimated that damages from surface water flooding could increase by $60-220 \%$ over the next 50 years (Adaptation Sub-Committee, 2012). More recent estimates suggest the Expected Annual Damage (EAD) from surface water flooding could increase by $135 \%$ in England by the 2080s under a $4^{\circ} \mathrm{C}$ climate scenario (Sayers et al., 2015).

\subsection{Surface water flood risk management}

The complexity of processes that influence surface water flooding means that it is extremely challenging to predict the occurrence and extent of events, limiting the ability to warn and plan for future risks (Houston et al., 2011). This and the large number of stakeholders involved (including water companies, developers, insurers, planners, local authorities and national government agencies); large data requirements for mapping and assessing surface water flood risks; lack of funding and capacity at local level; and lack of coordination of the different surface water flood risk management options, makes managing this type of flooding a complex issue.

Yet, effective management of surface water flood risk is critical to ensure that the UK can mitigate and adapt for future floods, such as those seen in 2007, in a cost effective manner. In this paper, we examine how different combinations of surface water flood risk management options affect local surface water flood risk in the context of different climate change scenarios. In particular, we focus on Sustainable Drainage Systems (SUDS), property level protection measures (PLPMs) and the new UK flood insurance scheme Flood Re, all identified as key measures for helping to manage and reduce flood risks in the UK (Adaptation Sub-Committee, 2012; HM Government, 2013).

SUDS aim to reduce surface water flooding by minimizing runoff (by reducing impermeable surfaces in urban areas) and store or convey surface water so that it does not cause harm and, as far as possible, does not enter sewers. In England, the use of SUDS was recommended by the Pitt Review (2008) and since April 2015 have been a requirement under amended planning guidance for all new developments of ten or more properties at risk of flooding (DCLG, 2014).

PLPMs are increasingly considered as an alternative or complement to other flood defence activities, used by property owners aimed at flood resistance (preventing or reducing the amount of water that gets inside the house) or flood resilience (reducing the damage water causes when water gets inside a house). PLPMs are applicable across flooding types, including surface water flooding, and are most cost-beneficial for frequent low-level flooding (Adaptation SubCommittee, 2011). The Pitt Review highlighted the potential for PLPMs to minimize damage from flood water and recommended that local authorities extend eligibility for home improvement grants and loans to include flood resistance and resilience products for properties in high flood risk. Defra and the Environment Agency (EA) ran grant schemes installing this equipment in over 2000 homes between 2007 and 2011, and following winter flooding in 20132014 the government introduced a repair and renew grant scheme to help homes affected to implement PLPMs. It is estimated that up to 330,000 properties in England could benefit from PLPMs by 2035 (Adaptation Sub-Committee, 2011). 
The third option we focus on is flood insurance, which compensates householders for flood losses, but is increasingly also seen as a possible means to incentivize risk prevention and adaptation actions. The growing losses from extreme weather events have re-intensified the discourse on the role of insurance in addressing flood and other climate risks (Surminski, 2014). While insurance is widely considered as an efficient financial tool that shifts resources away from ad hoc post-event payments, current loss trends are putting pressure on the affordability and availability of flood insurance - a challenge that is expected to increase, due to socio-economic drivers and climate change (e.g. Paudel et al., 2015). The example of surface water flood risk in the UK highlights these challenges for an existing insurance scheme and the new flood reinsurance scheme, Flood Re, designed to support households at highest flood risk.

\subsection{UK flood insurance}

Flood insurance across the UK is unique amongst most other national schemes as under the Statement of Principles (SoP) it is provided entirely by the private market. Financial risk transfer (i.e. compensation to flooded households financed by all policy holders) is provided by the insurance industry, while responsibility for flood risk reduction is primarily placed on the government (national and local) who commit to flood risk management activities such as the construction of flood defences and the regulation of water utilities who construct and maintain sewers. This agreement was extended for another five years in 2008, with properties built after 2009 then excluded from the SoP. In 2013 a new agreement was reached between the UK government and insurance industry with the creation of Flood Re, a new insurance pool for highrisk properties, which came into operation in Spring 2016. Households under low to normal flood risk will still be provided with insurance as standard, whilst the flood element of the home insurance policy for the 1-2\% of highest risk properties can be passed to Flood Re by insurers. The premiums offered for high risk households are fixed, roughly dependent on property values. Flood Re will be funded by these premiums and an annual levy taken from all policyholders and imposed on insurers according to their market share (Surminski and Eldridge, 2015).

While the change in the flood insurance scheme has been triggered by concerns of insurers about rising flood losses and concerns of at risk homeowners over future affordability, it remains unclear if and how Flood Re will be able to cope with future risks and fulfil its tasks. While the recent flood loss trends in the UK are largely due to socio-economic factors, such as more development in exposed areas, climate change is expected to exacerbate these impacts (IPCC, 2013). One important aspect, therefore, is if and how insurance can be integrated into overall risk management and climate change adaptation efforts.

Concerns have also arisen over the financial sustainability of Flood Re, and that its costs will remain higher than benefits delivered (Defra, 2013, p.30); as climate change has not been incorporated into the Flood Re risk modelling despite its 25 year outlook (Surminski and Eldridge, 2015); as Flood Re was not designed with risk reduction in mind and offers no incentives or formal mechanisms to encourage household level flood risk reduction (ibid.); and as implications of the scheme, and potential negative and positive feedbacks, have not been considered in parallel with other flood risk management interventions such as SUDS and PLPMs. 


\subsection{Aims and objectives}

The above concerns over Flood Re and how it can be integrated into overall risk management and climate change adaptation efforts have underpinned our investigation. Analysing the outcomes of such an insurance reform and its potential integration with flood risk management and climate change, requires a model that can simulate the dynamics of flooding, changing levels of risk, and the choices made by different stakeholders. An agent based model (ABM) was developed for Greater London to facilitate such interactions and dynamics to be considered in a single framework (Dubbelboer et al., 2016). In this study the ABM is utilized to investigate the specific effect of the insurance reform, its potential integration with flood risk management options, and implications of future climate change on this dynamic. The ABM is applied to a case study of the London Borough of Camden, an area at high risk of surface water flooding. However, the modelling approach could also be extended to other areas in the UK or specific situations in other countries (dependent on availability of relevant data and computational resources), including those where new climate insurance schemes and/or flood risk management strategies are planned. Section 2 provides an introduction to the case study area. Section 3 provides a summary of the ABM and its application in this study. Section 4 presents key findings and a discussion of the results. Section 5 reflects on these findings further, with final conclusions presented in Section 6.

\section{Case study of Greater London}

Floods are a major issue for London as it is vulnerable to tidal, fluvial, surface water, sewer and groundwater flooding. However, surface water flooding is considered the most likely cause of flooding and poses the greatest short-term climate risk to London (Greater London Authority, 2011a). It is acknowledged as a challenge in the London Climate Change Adaptation Strategy (ibid.). Yet, while there are several plans relevant for the management of flood risks in London the need for further quantification of risk and information to support adaptation options is often highlighted (Greater London Authority, 2011b).

Increased population and reduced urban surface permeability due to densifying development mean that London's aging drainage systems are under pressure. Around 680,000 properties are estimated to be at risk, with 140,000 Londoners at high risk and another 230,000 at medium risk (Greater London Authority, 2014). The number of residential properties prone to surface water flooding has been increasing from 2001 to 2011, as has the proportion of urban land covered with manmade surfaces (HR Wallingford, 2012). Because of the scarcity of undeveloped land which is not otherwise protected for recreational or environmental purposes, over $96 \%$ of new developments in London in recent years have been on brownfield sites. However, many of the remaining brownfield sites for development are in flood risk zones (Greater London Authority, 2009), with developments in such areas increasing by 0.5 to $0.7 \%$ per year from 2008 (Adaptation Sub-Committee, 2012).

The London Borough of Camden (Fig.1) encompasses an area of $21.8 \mathrm{~km}^{2}$ and a population of approximately 228,400 people (Greater London Authority, 2015b). Surface water flooding poses a large risk to Camden due to the nature of summer thunderstorms and the topography of the area, with a historic precedent for such events (Drain London, 2011). The area is not at risk of flooding from the River Thames or any other open rivers. 

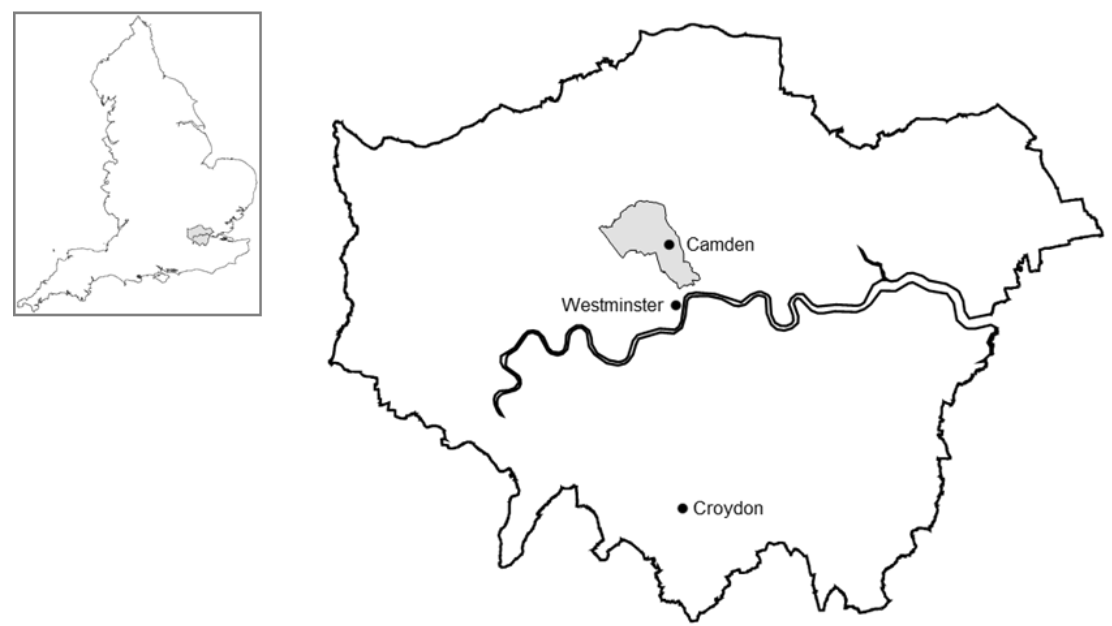

Figure 1: The boundary of Greater London study and the London Borough of Camden and the location in England (inset)

\section{Methodology}

\subsection{Overview of the Agent-Based Model}

An agent-based approach considers the simple and complex phenomena that may result from interactions between different agents in a shared environment. ABMs provide a bottom-up approach for understanding such dynamic interactions in complex systems, and can provide an improved understanding of systems by simulating these systems and their evolution (Bandini et al., 2009). In addition, by adjusting certain model parameters ABMs can be used to investigate key drivers, scope, and limits for future evolution of these systems, and visualize possible strategies and evolutionary pathways. As such they have a number of advantages as support tools for policy making, including their accessibility and flexibility for testing different conditions and behavioural rules (van Dam et al., 2012), with their application to simulating dynamics within geographical systems seeing a considerable increase over the last decade (Crooks and Heppenstall, 2012).

In this paper, we use the novel ABM developed for Greater London (Dubbelboer et al., 2016)., developed to simulate the dynamical evolution of flood risk and vulnerability, and facilitate an investigation of insurance mechanisms in London. Figure 2 provides an overview of the ABM, its key processes and interactions summarised below and in Section 3.2. In addition, a copy of the model, full documentation including model parameters, values and sources, model verification and sensitivity analysis are available online at https://www.openabm.org/model/4647/version/3/view). 


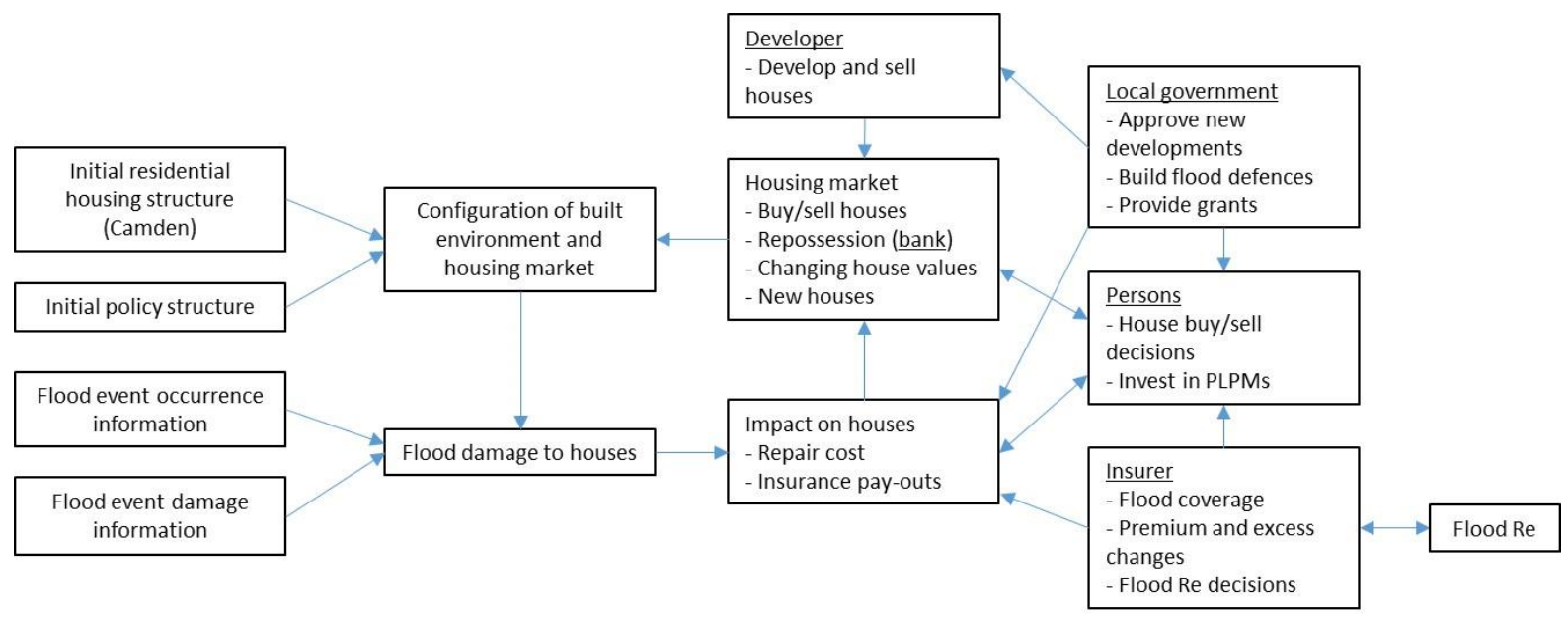

Figure 2: An overview of the key processes and interactions in the ABM

The ABM was parameterized based on a large array of data sources and developed around GIS data. A key input to the ABM is a probabilistic surface water flood event set (Jenkins et al., 2015). The event set was based on detailed surface water flood depth maps generated for Greater London for 1 in 30, 1 in 100, and 1 in 200 year return period rainfall events as part of the Drain London project, established by the Greater London Authority (2015a) to help predict and manage surface water flood risk, improve knowledge of the surface water drainage system and areas at most risk of flooding, and look at options to reduce future risk. The maps were modelled using a linked 1D2D hydraulic model of Greater London Boroughs constructed using TUFLOW (Two-Dimensional Unsteady Flow) software). This included a virtual representation of the ground topography and then applying water to the surface using a computational algorithm to determine the direction, depth and velocity of the resulting flows (modelling details are included in London Borough Surface Water Management Plans, e.g. see The Royal Borough of Kensington and Chelsea (2014), and Jenkins et al., 2015).

By overlaying the spatial flood maps onto residential building data, properties at risk of surface water flooding, and the flood depth, were identified. Economic damages to residential buildings were estimated using established flood depth-damage functions (Penning-Rowsell et al., 2010). This provided an estimate of damage to residential buildings based on building type and age.

However, as the Drain London data represents the modelled effect of a uniform rainfall event across the whole of Greater London, while in practice rain storms are spatially heterogeneous. A spatial hourly Weather Generator (WG) conditioned upon the UK's probabilistic climate projections (UKCP09) (Kilsby et al., 2011) was used to produce synthetic time series data of spatial rainfall events for a baseline period (1961-1990), the 2030s (2020-2040), and 2050s (2040-2060) under a high $(\mathrm{H})$ emission scenario. This is comparable to the latest generation IPCC Representative Concentration Pathway (RCP) 8.5 which, compared to the other RCPs, is the pathway with the highest greenhouse emissions which inter alia. combines assumptions about high population growth and modest rates of technological change and energy intensity improvements (Moss et al., 2010). The extent and spatial heterogeneity in surface water flood events was captured by rescaling the homogenous maps for each simulated flood event detected using the WG. 
Based on the estimated economic damage to houses for given flood return periods, a probabilitydamage curve is estimated annually for every house in the model, and surface water flood risk calculated as the area under the curve. Based on the formula in Bevan and Hall (Bevan and Hall, $2014, \mathrm{p} .17)$ in any given year $(\mathrm{t})$, the risk $\left(r_{i}, t\right)$ is given by:

$$
r_{i, t}=\int_{0}^{\infty} D\left(x_{t}\right) f\left(x_{t}\right) d x_{t}
$$

where, $D\left(x_{t}\right)$ is a damage function with $x$ changing overtime, $f\left(x_{t}\right)$ is the flood probability distribution.

Household flood risk is recalculated every year to reflect dynamic changes in the model due to investment in flood protection measures. If PLPMs or SUDS are installed then the initial estimated household flood damage data of residential buildings is reduced by $75 \%$ or $35 \%$ respectively (see section 3.2.2 below). The household damage from floods of given return periods does not change under the future climate scenarios, but the probability of such events occurring do. In this analysis, to illustrate the effect of climate change on surface water flood risk the probability damage-curves are adjusted accordingly for each climate scenario to reflect the change in probability of events.

\subsection{Summary of key agents and assumptions}

The ABM includes six different agents: people (who are assigned a status based on their situation: either homeowner, homebuyer or home seller), houses, an insurer, a bank, a developer and a local government, each with their own behaviour. Table 1 provides a summary of the main agent behaviours which underlie the model, with further details related to insurance and flood risk reduction options below.

\begin{tabular}{ll}
\hline \multicolumn{1}{c}{ Agent } & \multicolumn{1}{c}{ Main Behaviours } \\
\hline People & Decide to buy or sell properties \\
& Required to renew flood insurance annually \\
& Pay household fees \\
& Decide whether to invest in PLPMs (assumed that $1 \%$ of homeowners invest proactively per \\
& year, while $34 \%$ invest reactively following a flood) \\
& May consider flood risk when considering to purchase a new property \\
\hline Insurer & Estimates household surface water flood risk for every property in model (it is assumed that \\
& where in place they account for PLPMs and SUDs in these estimates) \\
& Sets insurance premiums and excess levels for every property in model \\
& Provides all households with flood insurance \\
& Decide whether it is cost effective to place high risk properties into Flood Re \\
& Provide compensation, minus the excess, to properties following a flood event \\
\hline Local Government & Invest up to $80 \%$ of their local flood defence budget (or more in the year of a flood event) in \\
& SUDS projects which protect houses at highest risk of flooding and provide a cost-benefit ratio \\
of 1:5 or greater & Invest up to $20 \%$ of their local flood defence budget to provide $£ 5000$ grants to households \\
investing in PLPMs & Evaluate and approve/reject property development plans based on their financial benefits and \\
flood risk & Sell land to developers for approved property developments \\
\hline If demand for new properties outstrips available properties on the market propose to build new \\
properties to meet demand \\
Identify optimal land to maximise profits from developments, within allocated development \\
areas and the local governments planned development trajectory
\end{tabular}


Submit development proposal to be approved by the local government

Build new houses (initially assumed that $50 \%$ of all houses built will have SUDS) and sell on the market

Bank $\quad \begin{aligned} & \text { Reposes houses if the owners are unable to afford household fees for three consecutive years } \\ & \text { Sell houses on market }\end{aligned}$

Table 1: Summary table of main agent behaviours

\subsubsection{Insurance}

In this analysis we only model the technical side of flood insurance and not the commercial side (i.e. competition between insurers, which might modify the offered premium). As we are focusing on surface water flooding we limit the insurer's attention to the surface water flood history of a house and the estimated surface water flood risk. In the ABM we assume that an insurer has detailed information that provides an estimate of surface water flood risk (equation 1). Based on that risk estimate and a flat administration cost the insurance premium and excess (the fixed value of each claim the homeowner has to pay) is calculated for each household. The insurer first sets the flood insurance excess for all houses. The assumption is made that the flood insurance excess amount is non-negotiable and is initially equal to $£ 200$ per claim on an annual policy. Houses hit during a surface water flood event will see their insurance excesses increase by $1 / 3$ rd, up to a maximum of $£ 2500$ (House of Commons Environment, 2013). The surface water flood risk estimates of houses $(h)$ are summed across all houses in flood risk $(n)$ in the model, representing the insurers expected annual loss $(E A L)$.

$$
E A L=\sum_{h=1}^{n}\left(r_{i, t}\right)
$$

The insurer deducts from this the total value of excesses $(e)$ paid and the total base flood insurance premium $(b)$ paid by all households $(a)$ in the model, assumed to be $£ 50$ per house per year to provide an estimate of the remaining annual loss $(R A L)$ that has to be covered. The remaining loss is spread across the households at risk of surface water flooding, by increasing their household flood insurance premium, $(P h)$, proportionally to the flood risk they are in. In this way people owning a house in surface water flood risk will receive a higher flood insurance premium.

$$
\begin{gathered}
R A L=E A L-\left(\sum_{h=1}^{a} e+b\right) \\
P_{h, t}=\left(r_{i, t}\right)_{h}+\left(\left(r_{i, t}\right)_{h}\left(\frac{E A L-R A L}{E A L}\right)\right)
\end{gathered}
$$

Insurers typically pass on risks above a set threshold by purchasing reinsurance on the global market. In this study the Flood Re scheme represents a government designed reinsurance entity to ensure continued insurance coverage for high flood risk properties in the UK. When switched on in the ABM the insurer has the option to re-insure eligible properties (those built prior to 2009) into Flood Re, with household flood insurance premiums fixed dependent on the property value (approximated according to the local property council tax rate ranging from $£ 210$ to $£ 1200$ in the study area). The insurer will have to pay to re-insure a household into Flood Re with a 
fixed premium per policy to the insurer also dependent on the property value. In this way the total compensation the insurer pays following a flood will be lower when the Flood Re option is selected, as they are no longer required to compensate the highest risk houses.

\subsubsection{Flood risk reduction options}

In the model the local government agent aims to reduce flood risk by investing in surface water flood reduction projects in the form of SUDS, and the provision of grants for PLPMs. It is assumed that PLPMs and SUDS will reduce the estimated economic damage to protected houses by $75 \%$ (Thurston et al., 2008) or 35\% respectively (Defra, 2011). The amount the local government can spend on SUDS and grants for PLPMs every year is equal to the annual subsidy they receive from the national government and a small percentage of their income from selling land to the property developer and collecting property taxes from home owners. Initially it is assumed that up to $80 \%$ of this budget can be spent annually on SUDS and 20\% for PLPM grants.

In the ABM every year the local government will proactively search for SUDS projects to invest in. Every project consists of a minimum of 100 houses that are in close proximity to each other. The projects are selected based on the flood risk of houses and the benefit-cost ratio that the local government would achieve for each project. From the identified projects the local government will try to build as many as it can with the budget it has, starting with the projects with the highest benefit-cost ratio.

The second task of the local government is the permitting of development proposals. The property developer will establish the number of houses it wishes to build based on the current unmet demand for housing in the model. The developer will locate land for development based on maps of planned opportunity areas in Camden, development targets set by the national and local government, and estimated land value. The land value, type of house to build, and the house price once completed are calculated based on the characteristics and values of the surrounding houses. It is initially assumed that $50 \%$ of all new properties are built with SUDS in place (Defra, 2011).

\subsection{ABM experiments conducted}

In this paper the ABM has been used to assess the role of Flood Re, PLPMs and SUDS in managing surface water flood risk, testing these options individually and in combination (Table 2). Secondly, in this paper each experiment setting was run using the flood event time series data for the baseline, $2030 \mathrm{H}$ and $2050 \mathrm{H}$ scenarios. The experiments were run at a yearly time-step for 100 simulations of the 30-year time series data corresponding to the baseline, 2030s and 2050s, to sample stochastic variability in the rainfall series. These repeated simulations are each driven by a new resampling of the uncertainties in the climate scenarios, so the statistical results also reflect these uncertainties. While Flood Re is intended to be a transitional scheme to be phased out over a 25-year period, in the interests of simplicity we have tested a steady state version of Flood Re over a 30-year simulation period.

\begin{tabular}{cccccc}
\hline $\begin{array}{c}\text { Experiment } \\
\text { Number }\end{array}$ & Experiment Name & $\begin{array}{c}\text { Current } \\
\text { Insurance } \\
\text { Scheme }\end{array}$ & $\begin{array}{c}\text { Flood Re } \\
\text { system }\end{array}$ & $\begin{array}{c}\text { Investment in } \\
\text { SUDS }\end{array}$ & $\begin{array}{c}\text { Investment } \\
\text { in } \\
\text { PLPMs }\end{array}$ \\
\hline 1 & Insurance & ON & Off & Off & Off \\
\hline 2 & Insurance+Flood Re & ON & ON & Off & Off \\
\hline
\end{tabular}




\begin{tabular}{cccccc}
\hline 3 & Insurance+SUDs & ON & Off & ON & Off \\
\hline 4 & Insurance+PLPMs & ON & Off & Off & ON \\
\hline 5 & Insurance+FloodRe+PLPMs & ON & ON & Off & ON \\
\hline 6 & Insurance+FloodRe+SUDs & ON & ON & ON & Off \\
\hline 7 & Insurance+FloodRe+SUDs+PLPMs & ON & ON & ON & ON \\
\hline 8 & Insurance+SUDs+PLPMs & ON & Off & ON & ON \\
\hline
\end{tabular}

Table 2: Combination of management options included for each different experiment

\section{Results}

Figure 3 shows the evolution of the average annual flood risk of houses over the 30 year simulations, each of which was run 100 times. The three sets of simulations correspond to the baseline climate and the $2030 \mathrm{H}$ and $2050 \mathrm{H}$ climate change scenarios. The simulation results reflect the trends in increasing frequency of events in the surface water flood event data set. Figure 3 highlights how the level of risk to properties also changes over time under experiment 1 , and provides a baseline case on which to compare the other experiments. The key drivers of the upward trend in surface water flood risk are increases in house prices in the modelled area; the development of new properties, often in areas of high flood risk, which drives up the overall flood risk of the area (the number of properties at risk of flooding increase to around 16,250 by the end of the 30-year period); and ongoing influences of surface water flood events.

Comparing across the climate scenarios the average surface water flood risk of properties increases, by up to $80 \%$ by year 30 in the $2050 \mathrm{H}$ scenario. The range in results for each climate scenario (coloured dots) reflect the 100 repeated runs which are driven by a new resampling of the uncertainties in the climate scenarios, as well as a representation of the potential for variability in behaviours in the model itself. This illustrates an increase in the variability between runs over time. This variability is largest for the $2050 \mathrm{H}$ scenario but even by year 30 the coefficient of variation is relatively small compared to the mean of the runs for the climate scenarios, and does not affect the overall trends seen across the climate scenarios. 


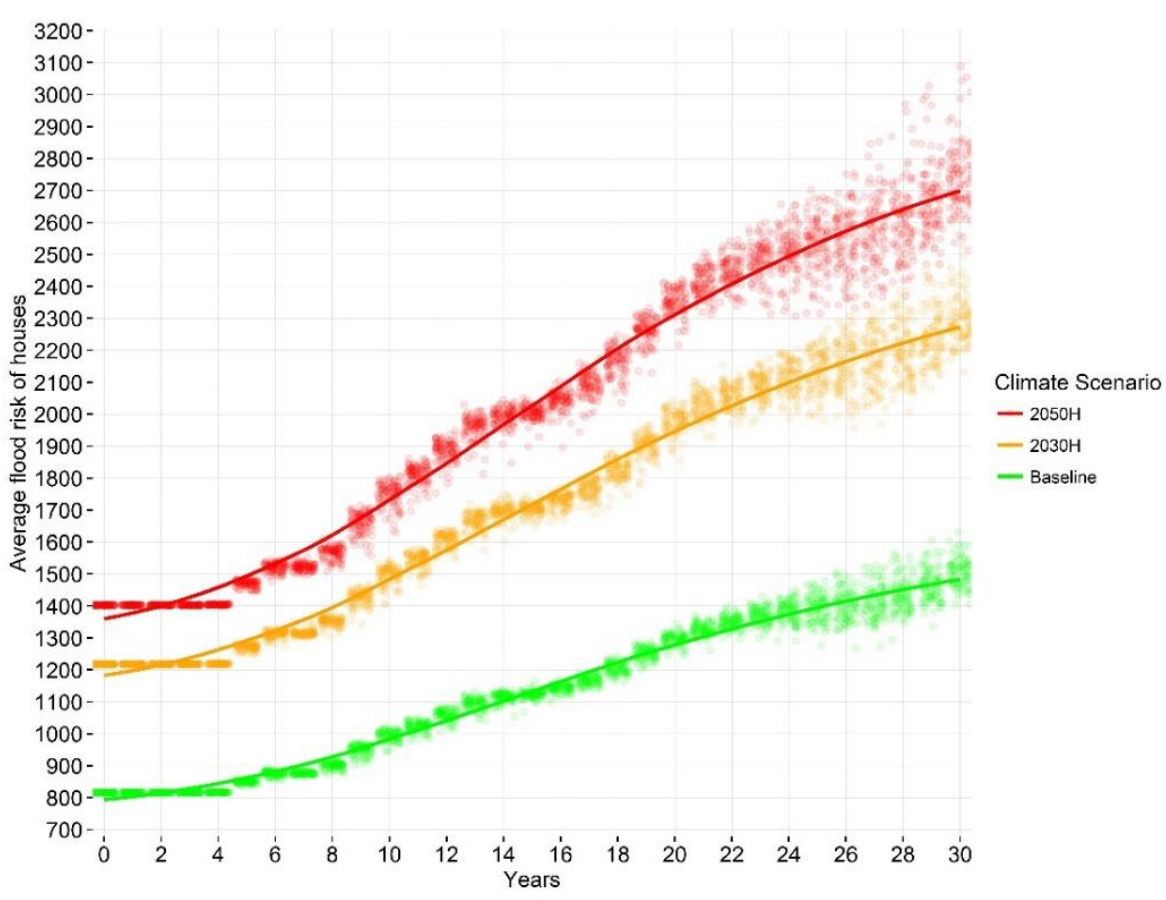

Figure 3: The average annual flood risk of houses ( $($ ) susceptible to surface water flooding (Experiment 1).

The role of Flood Re, PLPMs and SUDS in managing surface water flood risk have been tested by switching each option on and off in combination (Table 2). The below results illustrate the upper and lower bounds of the different options modelled, and potential benefits and limitations of different combinations of options. For the baseline climate scenario, Figure 4 highlights how the implementation of PLPMs (experiment 4) or SUDS (experiment 3) reduce the trend in the average surface water flood risk of houses over time, by around $10 \%$ and $15 \%$ respectively by year 30. The effectiveness of investment in SUDS and PLPMs are initially very similar even though installation of SUDS is assumed to reduce the potential flood damage by $35 \%$, whilst installation of PLPMs are assumed to reduce the potential flood damage by $75 \%$, and secondly, given that annually a larger number of properties are protected by PLPMs than SUDS in the model. This reflects the rationale of the local government in the model to build surface water flood defence projects in areas at highest risk of surface water flooding where the economic benefits and level of risk reduction will be the greatest. This is compared to people who are assumed to invest in PLPMs where emotional and affordability drivers are more diverse (Harries, 2012), and as the availability of grants is uniform across the model domain. 


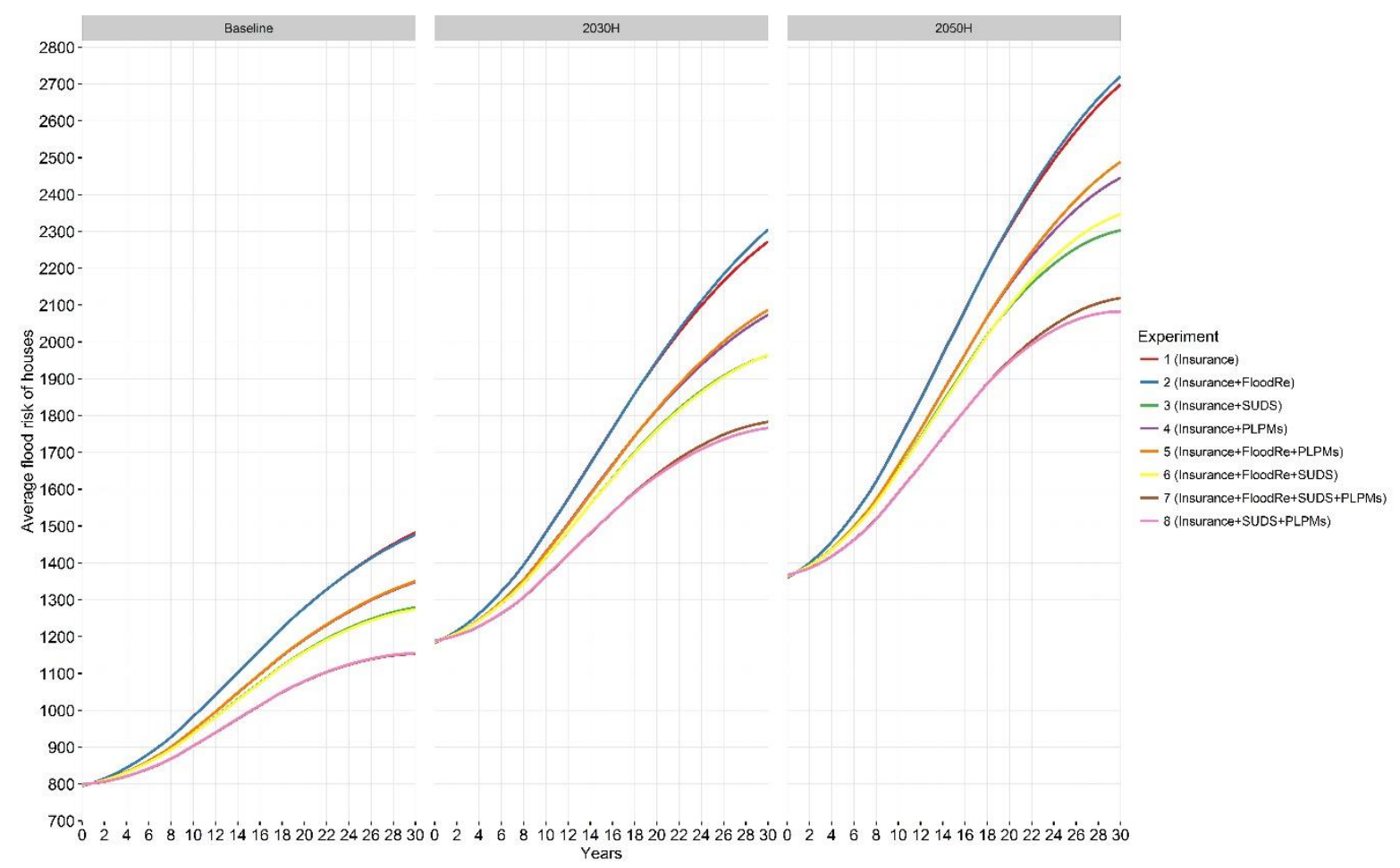

Fig. 4: The average surface water flood risk calculated for each of the experiments under the baseline, $2030 \mathrm{H}$ and $2050 \mathrm{H}$ climate scenarios.

The greatest benefits in terms of reduced risk are seen under experiments 7 and 8 where investments are made in both SUDS and PLPMs, with a 23\% decline by year 30 compared to experiment 1 for all three climate scenarios. The experiments which include Flood Re suggests that this scheme has no additional benefit in terms of overall risk reduction. In fact, in the $2030 \mathrm{H}$ and $2050 \mathrm{H}$ climate scenarios the opposite effect is seen with slightly higher levels of overall flood risk emerging by year 30. This trend is seen as an indirect result of the positive effects of Flood Re on the housing market in terms of house prices and the number of mortgage foreclosures. After several years of growing house sales the related increase in house prices means that home buyers start to search for different more affordable options, at which point the developer addresses this demand by developing more properties. Consequently, as house prices rise so does the investment in new developments, often in high flood risk areas, and subsequently overall flood risk rises in the model.

Figure 4 also highlights how the average household surface water flood risk continues to increase over time regardless of investment in risk reduction measures due to continued development of properties in flood prone areas. Whilst more stringent controls on the developer would reduce this risk it highlights the real pressure local governments are put under to develop more houses, and trade-offs which must be made when addressing flood risk and housing shortages.

The results also highlight the role of climate change in driving surface water flood risk. Even in the best case (experiments 7 and 8) where there is combined investment in flood risk management options the level of risk continues to increases above the worst-case baseline scenario, being $13 \%$ higher under the $2030 \mathrm{H}$ scenario and $33 \%$ higher under the $2050 \mathrm{H}$ scenario. 
This highlights the imperative to design surface water flood risk management strategies with climate change and future levels of risk in mind if impacts and costs are to stay at or below present levels.

However, Figure 5 highlights that Flood Re does achieve its purpose of keeping insurance premiums affordable for high risk properties. Under the baseline climate scenario household flood premiums initially remain below the thresholds where it would become economical to pass properties into Flood Re, and as such this has limited effect on average flood premiums in the first 8 years (remaining around $£ 70$ ). However, as premiums increase (reflecting the increased risk highlighted in figure 4), the potential benefits of PLPMs and SUDS for risk reduction and premiums are emphasized. The inclusion of Flood Re further reduces average premiums, from approximately $£ 650$ to $£ 280$ in the baseline scenario by year 30 . Even under the future climate change scenarios average premiums are limited to $£ 450$ to $£ 550$ by year 30 under experiment 7 , with a clear divergence in results which include/exclude Flood Re. The experiments without Flood Re illustrate much higher and steeper increases in average flood insurance premiums, upwards to $£ 1700$ for the $2050 \mathrm{H}$ scenario. An interesting observation is that the investment in SUDS or a combination of SUDS and PLPMs helps stabilize insurance premiums over time - a clear indicator that surface water risk management is essential to maintain the viability of flood insurance.

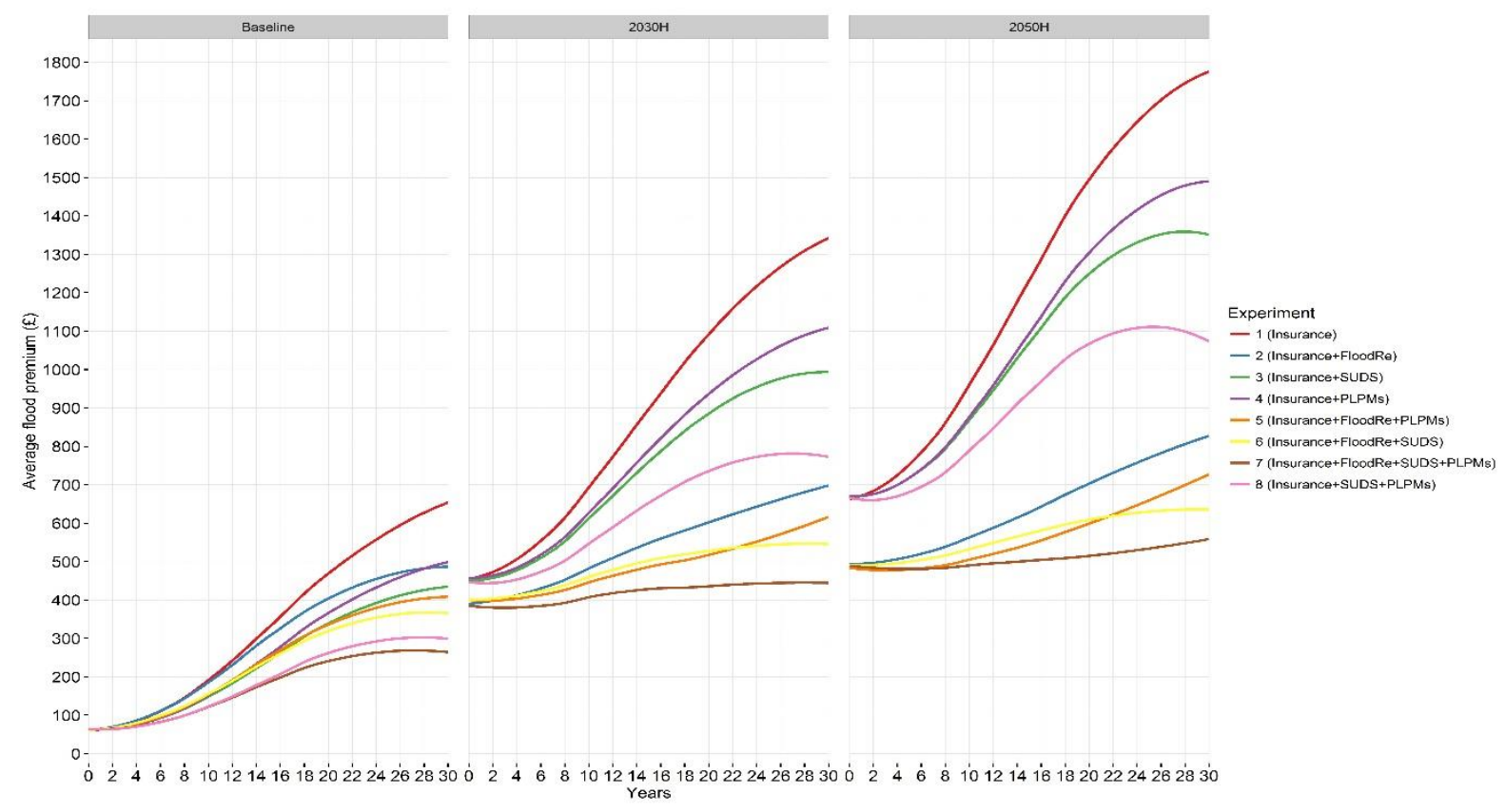

Fig. 5: Average flood premiums of houses in risk for each of the experiments under different climate scenarios.

Importantly, Flood Re has been designed to be a transitional solution, smoothing the move to more risk-based pricing in a competitive insurance market in the future, while securing affordability and availability of flood insurance (Defra, 2013). A key issue is how the scheme will cope with the increasing gap between subsidized and risk based premiums given urbanization and climate change. The potential gap is highlighted in this analysis through the comparison of experiments with and without Flood Re, with increasing divergence seen over time and across the climate scenarios. 
Furthermore, while our simulations indicate that Flood Re could ensure the affordability of insurance to homeowners, even under future climate change, this is modelled here without constraint on the number of properties which can be placed into Flood Re. Sensitivity analysis (available online at https://www.openabm.org/model/4647/version/3/view) highlighted relatively limited sensitivity of model outputs to a $10 \%$ and $20 \%$ reduction in total eligible properties that could be placed into Flood Re. Yet, any extension to the proposed coverage of Flood Re could have significant consequences for its funds and reinsurance cover, with affordable cover becoming harder to sustain under the future scenarios.

Figure 6 demonstrates that in the baseline scenario there is initially limited demand for Flood Re. Coinciding with the rise in surface water flood risk and premiums in the study area there is a sharp increase in properties in Camden placed in the scheme from around year 8, ranging by 20$58 \%$ by year 30 . However, under the future climate scenarios more properties are immediately ceded to Flood Re (based on their surface water flood history). This is around $40 \%$ of properties in flood risk that are eligible for Flood $\mathrm{Re}$ in the $2030 \mathrm{H}$ scenario and $75 \%$ in the $2050 \mathrm{H}$ scenario. For the $2030 \mathrm{H}$ scenario, the declining trend from year 16 is caused by an increasingly large share of houses in flood risk being new build houses, and as such these are not eligible for inclusion in Flood Re and act to reduce the percentage of total properties in flood risk which are placed into the scheme; and for experiments 5, 6, and 7 as more properties are protected by SUDS and/or PLPMs.

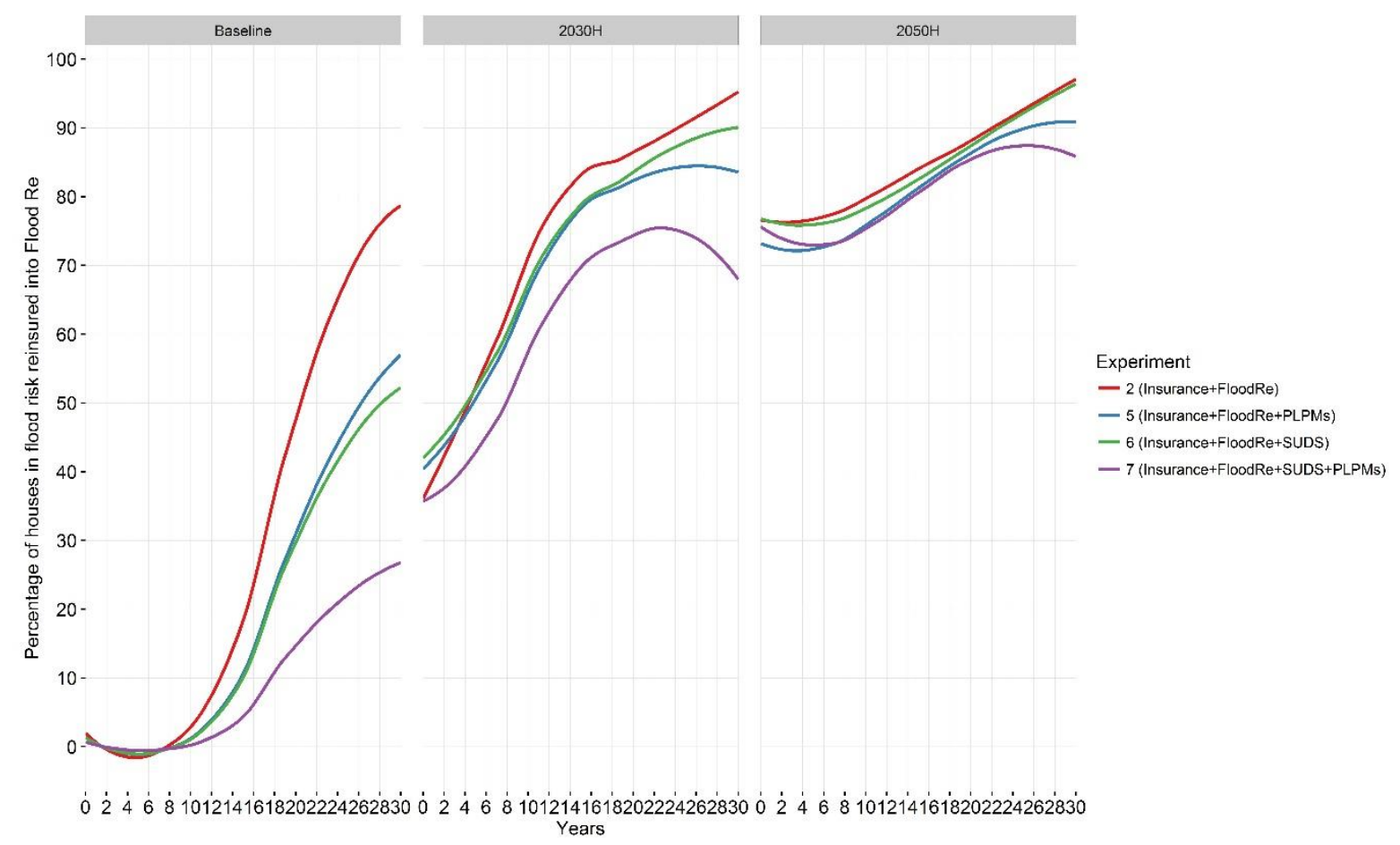

Fig. 6: The percentage of eligible properties at risk of surface water flooding reinsured into Flood Re

Finally, while Flood Re does not directly incentivize investment in PLPMs or SUDS, a positive feedback can be identified in that fewer properties are re-insured into Flood Re when these measures are in place. This is as PLPMs and/or SUDS are accounted for when estimating the potential damage to properties affected by flooding, and consequently lowers the insurers' 
estimate of flood risk of protected properties and in some cases the need to place the property into Flood Re. In these simulations a combination of insurance, SUDS, and PLPMs are shown to be most beneficial in terms of reducing the number of properties which are placed into Flood Re.

\section{Discussion}

The paper presents findings from the application of a novel ABM developed to model the dynamics of surface water flooding and changing surface water flood risk, and how adaptation and insurance decisions could affect future surface water flood risk in that dynamic. The analysis is innovative due to its dynamic nature and as different combinations of surface water flood risk management options can be modelled, to include structural adaptation options, insurance, and the specific case of Flood Re. While the focus of this paper is a case study of Camden the modelling approach is applicable to the broader situation in Greater London and could be extended to other areas in the UK or specific situations in other countries (dependent on availability of relevant data and computational resources), including areas where new insurance schemes are being developed.

Filatova (2015) highlights the need to move from conceptual modelling experiments to simulating real life situations through the use of available data if an ABM is to be applied for policy analysis, and be seen as robust by relevant stakeholders. In this study, the model used has been parameterized based on a large array of data sources and developed around GIS data to allow a realistic representation of residential buildings and surface water flood risk.

A limitation of this is that the ABM inevitability becomes more complex, and as with all models the results must be carefully interpreted given the underlying assumptions which are necessary given this complexity. Repeated simulations have been carried out to provide an assessment of model uncertainty and model verification has been used to test that all the relevant entities and relationships conceptualized were translated into the computational model correctly, and the model outputs remain robust given available evidence. The necessary simplifications and assumptions made in the development of the ABM are well documented (https://www.openabm.org/model/4647/version/3/view). Sensitivity analysis highlighted that model outputs are less sensitive to certain parameters, such as those related to the implementation and benefits of SUDS and PLPMs. Yet for others, such as those linked to the underlying housing market, the sensitivity of results becomes much higher. As far as possible these parameter values have been quantified and justified based on available data to support the analysis, but nonetheless are important to consider when interpreting the results.

It is also important to recognise that uncertainties are also embedded in input data such as the flood event data set. For example, whilst many studies adopt the approach of using a spatially uniform return period when mapping flood events, this can be unrealistic and lead to an overestimation of flood risk (Falter et al., 2015). The flood event data set used as input to the ABM offers more sophistication in that it combines Drain London flood depth data for three return periods with outputs from the weather generator. This enables sampling of spatially heterogeneous rainfall events and corresponding flood depth and extent, however, the re-scaled flood depth maps are still only able to demonstrate consequences of the rainfall simulation on a $5 \times 5 \mathrm{~km}$ grid, and it assumes that the flood depth and extent of heterogeneous rainfall over the study area will be the same as modelled under the Drain London scenarios of homogenous rainfall return periods which, as noted above, may have been overestimated. 
However, the ability of the model to incorporate different agents with their own behaviours; flexibility for testing different conditions and behavioural rules; flexibility to test and evaluate different policies and options; and the ability to visualize and quantify this in a spatial and dynamic manner, highlights the potential benefits of such a modelling approach. As such, it is a useful tool which can be utilized to explore and enhance our understanding of how flood risk, management options, and the new Flood Re scheme may operate in practice, and the potential impacts on different agents and the Flood Re scheme itself.

The results presented highlight how climate change and socio-economic development can exacerbate current levels of surface water flood risk, and that the investment in a combination of resilience measures (PLPMs and SUDS) would yield the biggest surface water flood risk reduction. This highlights the need for further investment and provision of grants for PLPMS and adds support to the current reviews and government led pilot schemes into PLPMs being undertaken in the UK. However, in our model even with SUDS and PLPMs in place the average surface water flood risk continued to increase over time, and under no experiment did it stabilize or decline. Given the implications of climate change on surface water flood risk this illustrates the implications of further trade-offs between future development plans and flood risk management.

Our analysis shows that Flood Re would achieve its aim of securing affordable flood insurance premiums. However, our findings also highlight that the new pool would be placed under increased financial strain if challenged with increasing risk as highlighted by the future climate change projections. A further benefit of the method employed is that the ABM also provides a platform to investigate the transitional mechanisms recently proposed as part of the Flood Re scheme (Flood Re, 2016), as well as how changes to regulatory measures and the roles and behaviour of different stakeholders could be enhanced to support surface water flood risk reduction under future climate change (Crick et al., 2016). This is particularly important as our results highlight that Flood Re is shown to have no additional benefits in terms of overall risk reduction.

This supports concerns that the new scheme is missing an opportunity to contribute to risk reduction, which is important to its own resilience under future climate change (Adaptation SubCommittee, 2015). It also raises concerns about issues of moral hazard as it could de-incentivize flood risk reduction at a household level and dissuade homeowners from investing in PLPMs (Surminski and Eldridge, 2015). While this is a key design issue for Flood Re, it is also highly relevant for other insurance schemes.

\section{Conclusion}

Whilst there is extensive literature on fluvial and coastal flood risk, surface water flood risk has received less attention both nationally and internationally. The number of stakeholders involved, and varying degrees of responsibility across government and other agents further complicates the ability to manage surface water flood risk in an integrated manner.

Our particular interest in the interactions between flood insurance in the UK and surface water flood risk management stems from the current changes facing the industry with the introduction of the new Flood Re pool in Spring 2016. However, efforts to reform the insurance arrangements have been predominantly focused on dealing with the affordability of insurance, without considering the implications of alternative mechanisms for managing and reducing the 
underlying risks, particularly important given future projections of climate change and urbanization. Reflecting on evidence emerging from other European and international flood insurance schemes, we notice that this is not an exception, but rather the norm (Surminski and Eldridge, 2015). Yet, depending on its design and implementation, an insurance scheme can send signals to policy makers in support of flood risk management policies, which would address risk levels, for example through changes in the planning system and building regulations. Our investigation finds that the new Flood Re scheme does not enhance this policy link nor the incentivisation of home resilience, which is a missed opportunity.

Until now this issue has not received sufficient attention due to lack of data or analysis. The results presented here provide insights into the implications of current policy for land use planning, national and local adaptation, and flood risk management, and highlights that there is still discord between these. The potential of integrating these options and using Flood Re along with other measures such as grants for PLPMs and enhanced planning policy have been investigated through the use of a novel ABM, and results quantified to account for the role of different actors, changing risk under future climate change, and potential uncertainties. This analysis suggests further policy on planning developments, increased investment in SUDS for new and existing properties, and investment in PLPMS is required. The Flood Re scheme could help with this transition if it were able to incentivize such measures.

These issues are likely to become more apparent under climate change and urbanization, both in the UK in urban areas like Camden, as well as in those countries that are currently experimenting with climate insurance. Our study shows that climate change and socio-economic risk drivers are expected to widen the gap between 'affordable' flood insurance premiums and premiums that reflect the technical price of flood insurance unless we increase our efforts to foster resilient to surface water and other flood events in the future.

\section{Acknowledgments}

The authors would like to thank Giorgis Hadzilacos, Jonathan Gascoign, Igor Nikolic, Jan Dubbelboer, and Jillian Eldrige for their insights and support.

This paper has benefited from research undertaken as part of the ENHANCE Project (Enhancing risk management partnerships for catastrophic natural hazards in Europe), funded under the Seventh Framework Programme of the European Union under grant agreement No 308438.

The authors would also like to acknowledge the financial support of the UK Economic and Social Research Council (ESRC) through the Centre for Climate Change Economics and Policy as well as the use of the University of Oxford Advanced Research Computing (ARC) facility in carrying out this work (http://dx.doi.org/10.5281/zenodo.22558).

\section{References}

Adaptation Sub-Committee. Adapting to Climate Change in the UK. measuring progress. Adaptation sub-committee, London, 2011, pp. 101.

Adaptation Sub-Committee. Climate Change - Is the UK preparing for flooding and water scarcity? Committee on Climate Change, London, 2012, pp. 102.

Adaptation Sub-Committee. Letter: Designing Flood Re to encourage Flood Risk reduction. Adaptation sub-committee, London, 2015. 
Bandini S, Manzoni S, Vizzari G. Agent Based Modeling and Simulation: An Informatics Perspective. Journal of Artificial Societies and Social Simulation 2009; 12.

Bevan K, Hall J. Applied Uncertainty Analysis for Flood Risk Management. Imperial College Press, London, 2014, pp. 684.

Blanc J, Hall JW, Roche N, Dawson RJ, Cesses Y, Burton A, et al. Enhanced efficiency of pluvial flood risk estimation in urban areas using spatial-temporal rainfall simulations. Journal of Flood Risk Management 2012; 5: 143-152.

Cabinet Office. National Risk Register of Civil Emergencies. The Stationery Office Limited, London, 2015, pp. 54.

Crick F, Jenkins K, Surminski S. Strengthening insurance partnerships in the face of climate change - insights from an agent-based model of flood insurance in the UK. Centre for Climate Change Economics and Policy Working Paper No. 271 \& Grantham Research Institute on Climate Change and the Environment Working Paper No. 241. Grantham Research Institute on Climate Change and the Environment, London, 2016.

Crooks AT, Heppenstall AJ. Introduction to Agent-Based Modelling. In: Heppenstall AJ, Crooks AT, See LM, Batty M, editors. Agent-Based Models of Geographical Systems. Springer, London, 2012, pp. 85.

DCLG. Sustainable drainage systems. House of Commons: Written Statement (HCWS161). Department for Communities and Local Government London, 2014.

Defra. Commencement of the Flood and Water Management Act 2010, Schedule 3 for Sustainable Drainage: Impact Assessment. No: Defra 1367. Defra, London, 2011, pp. 42.

Defra. The UK Climate Change Risk Assessment 2012: Evidence Report. Defra, London, 2012, pp. 488.

Defra. Securing the future availability and affordability of home insurance in areas of flood risk Defra, London. Avaliable at: https://consult.defra.gov.uk/flooding/floodinsurance. Accessed: 25th June 2015, 2013.

Drain London. Surface Water Management Plan: London Borough of Camden. Camden Council, 2011 , pp. 84.

Dubbelboer J, Nikolic I, Jenkins K, Hall J. An Agent-Based Model of Flood Risk and Insurance. Journal of Artificial Societies and Social Simulation 2016; 20.

Environment Agency. The costs of the summer 2007 floods in England. Environment Agency, Bristol, 2010.

European Water Association. EWA Expert Meeting on Pluvial Flooding in Europe. Final Report. EWA, Brussels, Belgium, 2009.

Falter D, Schröter K, Dung NV, Vorogushyn S, Kreibich H, Hundecha Y, et al. Spatially coherent flood risk assessment based on long-term continuous simulation with a coupled model chain. Journal of Hydrology 2015; 524: 182-193.

Filatova T. Empirical agent-based land market: Integrating adaptive economic behavior in urban land-use models. Computers, Environment and Urban Systems 2015; 54: 397-413.

Flood Re. Transitioning to an affordable market for household flood insurance: The first Flood Re transition plan. Flood Re, London, 2016.

Greater London Authority. London Regional Flood Risk Appraisal. In: The Mayors London Plan, editor. GLA, London, 2009, pp. 62.

Greater London Authority. The London Climate Change Adaptation Strategy. Greater London Authority, London, 2011a, pp. 125. 
Greater London Authority. The London Plan: Spatial Development Strategy for Greater London. Greater London Authority, London, 2011b.

Greater London Authority. Flood risks in London: Summary of findings. Greater London Authority, London. Accessed 13th March 2015. Avaliable at: https://www.london.gov.uk/sites/default/files/14-04-07Flood\%20risk\%20slide\%20pack\%20-\%20FINAL_0.pdf., 2014.

Greater London Authority. Drain London. Greater London Authority, London, Archived at http://www.webcitation.org/6YIlgF36K, 2015a.

Greater London Authority. London datastore http://data.london.gov.uk/. Greater London Authority, London, 2015b.

Hall J, Sayers P, Dawson R. National-scale assessment of current and future flood risk in England and Wales. Natural Hazards 2005; 36: 147-164.

Hall JW, Meadowcroft IC, Sayers PB, Bramley ME. Integrated flood risk management in England and Wales. Natural Hazards Review 2003; 4: 126-135.

Hammond MJ, Chen AS, Djordjević S, Butler D, Mark O. Urban flood impact assessment: A state-of-the-art review. Urban Water Journal 2015; 12: 14-29.

Harries T. The anticipated emotional consequences of adaptive behaviour - impacts on the takeup of household flood-protection measures. Environment and Planning A 2012; 44: 649668.

HM Government. The National Adaptation Programme: Making the country resilient to a changing climateThe Stationery Office, London, 2013.

House of Commons Environment, Food and Rural Affairs Committee, Managing Flood Risk. Third Report of Session 2013-14. Volume I. The Stationery Office, London, 2013.

Houston D, Werritty A, Bassett D, Geddes A, Hoolachan A, McMillan M. Pluvial (rain-related) flooding in urban areas: the invisible hazard. Joseph Rowntree Foundation, 2011.

HR Wallingford. Development of spatial indicators to monitor changes in exposure and vulnerability to flooding and the uptake of adaptation actions to manage flood risk in England: Results 2012. HR Wallingford Ltd, Oxfordshire, 2012, pp. 56.

IPCC. Climate Change 2013: The Physical Science Basis. Contribution of Working Group I to the Fifth Assessment Report of the Intergovernmental Panel on Climate Change. Cambridge, United Kingdom and New York, NY, USA: Cambridge University Press, 2013.

IPCC. Climate Change 2014: Synthesis Report. Contribution of Working Groups I, II and III to the Fifth Assessment Report of the Intergovernmental Panel on Climate Change. Cambridge, United Kingdom and New York, NY, USA: Cambridge University Press, 2014

Jenkins K, Hall J, Surminski S, Crick F. London Case Study: Flood risk and climate change implications for MSPs. ENHANCE deliverable 7.3: Risk scenarios and analysis. http://www.eci.ox.ac.uk/publications/downloads/jenkins15London_case_study_D7.3_ENHANCE.pdf 2015; Archived at: http://www.webcitation.org/6ZZSW0snK.

Kilsby C, Jones P, Harpham C, Glenis V, Burton A. Spatial Urban weather Generator for Future Climates, ARCADIA Task 3 Report. Avaliable at: http://www.arcc-cn.org.uk/wpcontent/pdfs/ARCADIA-7.pdf, 2011, pp. 8. 
Moss RH, Edmonds JA, Hibbard KA, Manning MR, Rose SK, Vuuren DPv, et al. The next generation of scenarios for climate change research and assessment. Nature 2010: 747756.

Paudel Y, Botzen WJW, Aerts JCJH. Influence of climate change and socio-economic development on catastrophe insurance: a case study of flood risk scenarios in the Netherlands. Regional Environmental Change 2015; 15: 1717-1729.

Penning-Rowsell E, Viavattene C, Pardoe J, Chatterton J, Parker D, Morris J. The Benefits of Flood and Coastal Risk Management: A Handbook of Assessment Techniques. Flood Hazard Research Centre, London, 2010, pp. 98.

Pitt M. Learning Lessons from the 2007 Floods. The Pitt Review. Cabinet Office, London, 2008.

Ramsbottom D, Sayers P, Panzeri M. Climate Change Risk Assessment for the Floods and Coastal Erosion Sector. UK Climate Change Risk Assessment. Defra, London, 2012.

Sayers PB, Horritt M, Penning-Rowsell E, McKenzie A. Climate Change Risk Assessment 2017: Projections of future flood risk in the UK. Research undertaken by Sayers and Partners on behalf of the Committee on Climate Change. Committee on Climate Change, London, 2015.

Surminski S. The Role of Insurance in Reducing Direct Risk - The Case of Flood Insurance. International Review of Environmental and Resource Economics 2014; 2013(7): 241278.

Surminski S, Eldridge J. Flood insurance in England - an assessment of the current and newly proposed insurance scheme in the context of rising flood risk. Journal of Flood Risk Management 2015.

The Royal Borough of Kensington and Chelsea. Surface Water Management Plan Appendix B Modelling Details. Avaliable at: https://www.rbkc.gov.uk/wamdocs/RBKC_Appendix_B_Modelling_Details_v4.pdf, 2014, pp. 18.

Thurston N, Finlinson B, Breakspear R, Williams N, Shaw J, Chatterton J. Developing the evidence base for flood resilience. FD2607/TR. Defra, London, 2008.

van Dam KH, Nikolic I, Lukszo Z. Agent-based modelling of socio-technical systems. Springer Netherlands, 2012, pp. 268.

Willems P, Arnbjerg-Nielsen K, Olsson J, Nguyen VTV. Climate change impact assessment on urban rainfall extremes and urban drainage: Methods and shortcomings. Atmospheric Research 2012; 103: 106-118. 